\title{
BM] Global Heatth Reimagining global health as the sharing of power
}

\author{
Kumanan Rasanathan, ${ }^{1}$ Jennifer J K Rasanathan ${ }^{2}$
}

To cite: Rasanathan $\mathrm{K}$, Rasanathan JJK. Reimagining global health as the sharing of power. BMJ Global Health 2020;5:e002462. doi:10.1136/ bmjgh-2020-002462

Received 5 March 2020 Accepted 5 March 2020

Check for updates

C Author(s) (or their employer(s)) 2020. Re-use permitted under CC BY-NC. No commercial re-use. See rights and permissions. Published by BMJ.

${ }^{1}$ Health Systems Global, Phnom Penh, Cambodia

BMJ Publishing Group, London, UK

Correspondence to Dr Jennifer J K Rasanathan; jjkrasanathan@gmail.com
The foundational documents of global health, including the WHO Constitution and the Declaration of Alma-Ata, ${ }^{12}$ affirm and reaffirm the importance of equality, equity and the human rights principles of participation, non-discrimination and accountability-as important ends in themselves, but also as essential to achieve improvements in health outcomes. In recent years though, the system of organisations and structures that comprise 'global health' has been increasingly indicted on the extent to which it reflects these values in its own operations-in particular, who is represented in decision-making and allocation of resources, and who is excluded.

Gender inequalities in global health institutions have been challenged by organisations such as Women in Global Health ${ }^{3}$ and Global Health 50/50 (GH5050), ${ }^{4}$ while the \#MeToo social movement has shown that global health is not a safe space from sexual harassment. ${ }^{56}$ Allied to growing calls to 'decolonise' global health (problematising the typical modus operandi of institutions and individuals in and from high-income countries acting on issues and individuals in low-income and middle-income countries), ${ }^{7}$ there is a growing intersectional interrogation of the political economy of global health. ${ }^{8}$

In this context, we welcome the publication of the third annual GH5050 report and accompanying Gender and Health Index, ${ }^{9}$ timed to coincide with International Women's Day. Taking gender analysis as an entry point, the report examines the policies and composition of 200 organisations working in global health and argues that global health is not fit-for-purpose to deliver on its Sustainable Development Goal (SDG) mandate to ensure health and well-being for all people. Here, we highlight three of its key findings and offer our reflections on the implications and questions the report raises.

First, despite a reported increase in the availability of workplace gender equality policies among the 139 organisations assessed over 3 years (from $44 \%$ in 2018 to $60 \%$ in 2020), there has been little progress in parity at the top. Gender parity in senior management, the report forecasts, will not be reached for another 54 years at the current rate of change. Few organisations address gender in a transformative manner, and more organisations have policies on gender equality in recruitment than other aspects of workforce diversity. Second, the report finds that only $17 \%$ of global health leaders are nationals of low-income or middle-income countries, while only $12 \%$ of global health organisations are headquartered in low-income and middleincome countries. Third, and most striking, the report demonstrates the mismatch between the programmatic focus of most global health organisations compared with SDG health targets by using sex-disaggregated data on the burden of disease associated with each target. In so doing, the authors point to the larger focus on maternal mortality compared with work on non-communicable diseases (NCDs), tobacco use, alcohol and substance use and traffic injuries, all of which disproportionately impact the health of men and boys. The applicability of these findings and the follow-on consequences and imperatives for action deserve consideration and scrutiny by all in global health.

As the report itself acknowledges, improvements in the metrics the report uses on gender equality do not necessarily translate to a fuller appreciation of the relationship between gender and health in global health organisations' workforce policies and way of working. We need much faster progress towards gender-balanced boards and genderequal leadership in global health as ends in themselves. But we also need to mitigate the risk that gender equality policies are tokenistic, 'tick box' exercises that allow organisations to get a better GH5050 score without substantively changing workplace culture, making opportunities for advancement more equitable or, crucially, enabling them to 
do their jobs better. Will greater gender parity in global health leadership improve the chances of achieving the SDG health-related targets? We need mechanisms that ensure that global health institutions take a gendertransformative approach, as critical to the pursuit of health for all, to ensure this is so in practice. ${ }^{10}$

The intersectional lens the report applies to its analysis of today's global health architecture is much needed. The sobering but probably unsurprising findings lead us to ask: what are the consequences of having almost $90 \%$ of global health organisations' headquarters in highincome countries? Or of having women from low-income and middle-income countries in only $5 \%$ of global health leadership roles? The report does not measure class as a factor. Efforts to improve diversity in elite settings (which global health undoubtedly is) tend to be captured by elite members of under-represented groups-those most fluent in the dominant discourses and with the social capital to be able to enter and function in these spaces with minimal disruption. Perhaps even more important than efforts to diversify global health leadership (especially given the entry barriers to these roles) is ensuring that rights-holders who are the intended beneficiaries of global health practice are included, consulted and employed in strategic planning, programmatic priority setting, implementation and accountability mechanisms.

The report's most interesting and original finding is its highlighting of the lack of attention to the health of men and boys, perhaps a vestige of the dominance of the Millennium Development Goals' (MDGs) health agenda even 5 years into the SDG era. Again, the implication is that 'gender and health' has too often served as a proxy for 'women's health', rather than engaging with contextspecific gender norms, roles and behaviours that manifest in divergent health outcomes among and between women, men and transgender people. The nuance that this report adds is that this disproportionately leads to neglect of the health of men and boys linked to NCDsand moreover, that unless we address this neglect and tackle the determinants of these inequalities, increasing equality in gender roles will perversely lead to worsening NCD outcomes for women as they adopt behaviours prevalent in men. We do not think the implication is that we should devote less attention in global health to reproductive and maternal health, given the global failure to achieve MDG 5 and continuing challenges with sexual and reproductive health and rights. But highlighting this gap is a further stimulus to more fully engage with the relationship between gender and health, and merits serious consideration and follow-up by global health funders, policy-makers and implementers. Although the report recognises the differing size, influence and power of the organisations it assesses, we would welcome a more detailed power analysis taking funding levels and impact into account, particularly disaggregating the quantitative findings further.

In conclusion, the GH5050 report calls not just for a moment of reflection but instead a moment of imagination for global health. We applaud the scale of the review of organisations, and especially the courage of the authors in moving beyond gender equality to a more comprehensive diagnosis of global health and its discontents. Their findings raise the uncomfortable question of whether global health leadership can be anything other than an elite activity. ${ }^{11}$ We hope the next edition will include qualitative research or even similar assessments in national contexts to further our understanding of the culture of global health. In the meantime, we should closely consider these findings and continue the task of reimagining global health as a practice of liberation and the genuine sharing of power.

Twitter Kumanan Rasanathan @rasanathan

Funding The authors have not declared a specific grant for this research from any funding agency in the public, commercial or not-for-profit sectors.

Competing interests None declared.

Patient consent for publication Not required.

Provenance and peer review Not commissioned; internally peer reviewed.

Data availability statement No additional data are available.

Open access This is an open access article distributed in accordance with the Creative Commons Attribution Non Commercial (CC BY-NC 4.0) license, which permits others to distribute, remix, adapt, build upon this work non-commercially, and license their derivative works on different terms, provided the original work is properly cited, appropriate credit is given, any changes made indicated, and the use is non-commercial. See: http://creativecommons.org/licenses/by-nc/4.0/.

\section{REFERENCES}

1 World Health Organization. Constitution of the World Health Organization. Geneva: World Health Organization, 1948.

2 World Health Organization, UNICEF. Declaration of Alma-Ata. USSR: Alma-Ata, 1978.

3 Dhatt R, Thompson K, Lichtenstein D, et al. The time is now - a call to action for gender equality in global health leadership. Glob Health Epidemiol Genom 2017;2:e7.

4 Clark H. Report card shows gender is missing in global health. Lancet 2018;391:918-20.

5 \#MeToo Meets Global Health: A Call to Action. Health Hum Rights 2019;21:133-9.

6 Zarocostas J. Hiv/Aids community divided over allegations about UNAIDS. Lancet 2018;391:391.

7 Saha S, Kavattur P, Goheer A. The C-Word: tackling the enduring legacy of colonialism in global health. Available: https://www. healthsystemsglobal.org/blog/341/The-C-Word-Tackling-theenduring-legacy-of-colonialism-in-global-health.html [Accessed 2 March, 2020].

8 Kapilashrami A, Hankivsky O. Intersectionality and why it matters to global health. Lancet 2018;391:2589-91.

9 Global Health 50/50. The global health 50/50 report 2020: power, privilege and priorities. London, UK, 2020. https://globalhealth5050. org/2020report/

10 Gupta GR, Oomman N, Grown C, et al. Gender equality and gender norms: framing the opportunities for health. Lancet 2019;393:2550-62.

11 Horton R. Offline: the pretensions of global health elites. Lancet 2020;395:672. 